\title{
A Journey from within: The Virtual Mentoring CASE Model
}

\author{
Hazel Owen ${ }^{1^{*}}$ and Rick Whalley ${ }^{2}$ \\ ${ }^{1}$ Ethos Consultancy New Zealand and CORE Education New Zealand \\ ${ }^{2}$ CORE Education, New Zealand \\ Email: hazelowendmc@gmail.com
}

\begin{abstract}
A shared 'learning journey' can open up multiple pathways, with each individual's journey shaped by their beliefs, values and prior experiences. There is a growing interest in Professional Learning and Development (PLD) that offers multiple ways to participate, apply and collaborate, in part by using the affordances of technology. Virtual and face-to-face professional learning provision, in particular mentoring, have differences. This paper extrapolates and applies the findings of two studies, drawing on the experiences of students in the Virtual Learning Network Primary study, and those of adult learners in the Virtual Professional Learning and Development programme. The authors identified four key stages that they then encapsulated in the virtual mentoring CASE (Contextual, Administration, Scaffolding, Empowering) Model. The model is situated within a mediated agency framework, which helps illustrate the complexity of contexts that influence the design of a PLD provision, and which can be used in a variety of situations.
\end{abstract}

Keywords: Professional development, mentor, kaiārahi, mentee, transformation, contextual.

\section{Introduction}

"Dig down into yourself for a deep answer" (Rilke, 2012. p12)

Although the 'learning journey' is now a bit of a cliché, it is a useful way to illustrate the myriad pathways and adventures involved in learning, including the mentor (mentors) and comrades a person chooses to collaborate with along the way, the rate of progress and the decisions they make that can change the course of their professional narrative. The journey is also the focus, rather than endpoint. One thing that everyone's journey share is their difference. Even people on the same journey will experience it differently because of their worldview, beliefs and values, the affordances, space and tools available, and the opportunities and constraints from the frameworks of educational institute that guide them. With the growing awareness that all learning experiences need to recognise these differences (Bolstad et al, 2012), it is no surprise that Professional Learning and Development (PLD) is being reconceptualised (Owen, 2015). So, how do we ensure that PLD provision is flexible, mobile, and personalisable enough to enhance everyone's journey? How can we find approaches that make the provision itself invisible by foregrounding and meeting the needs of the learner?

Virtual provisions are necessarily external to a professional learner's work-context, and yet to be effective they "cannot be separated from ... [the practitioner's] ecological contexts, or from the educational activities that they enhance" (Peled, Peled, and Alexander, 1994, p. 49). Therefore, the situating of virtual PLD is important because "many challenges [that] staff face are local ... and need to be addressed "on the ground"' (Stoll, 2004, p. 2). In addition, PLD that recognises sociocultural considerations has been reported to have a positive impact on student learning outcomes, partly because there is a direct connection between principles of effective teaching practices and consequent adaptation of those practices to local circumstances (Timperley, 2008).

This paper explores the notion of mediated agency to explain the process of virtual mentoring using the Virtual Mentoring CASE Model (Contextual data, Administration process, Scaffolding and Empowering process) developed from two studies undertaken by the authors. The authors believe that the model has the potential to guide organisations to develop their own virtual mentoring provision. The approach enables mentors to work alongside mentees on their personalised professional learning journey, encouraging robust discussions, helping explore alternative points of view, and supporting the practitioner to realise the power of 'transformational realisation'. 


\section{$2 \quad$ Literature Review}

\subsection{Mentoring in a Virtual Environment}

Mentoring has many definitions (Ives, 2008). In part, the sheer range of definitions is indicative of the way the mentoring / coaching dichotomy emerged, as well as the multiple influences from, for example, therapeutic and personal-development approaches (Williams, 2014). The situation is further complicated because mentoring practice includes coaching approaches (Kram, 1985), and many aspects of coaching have arisen directly from mentoring (Garvey, 2010).

In this paper, the authors use the definition whereby "mentoring is a developmental alliance between equals in which one or more of those involved is enabled to: increase awareness, identify alternatives, initiate actions and develop themselves" (Hay, 1995, p. 3). A developmental approach focuses on supporting a mentee's personal and professional development, rather than developing or enhancing a set of specific skills (e.g. working with Google Apps for Education) or knowledge set. The non-directive nature of the developmental approach provides opportunities for education practitioners (or small groups) to work with a mentor (mentor) in a collaborative, egalitarian, culturally responsive, supportive relationship where the desired outcome is positive change (Owen, 2015). The mentor works with a mentee to comprehend their situation, recognise suitable strategies and understand the implications of implementing those strategies.

Virtual mentoring has been around for a while (e.g. Single and Muller, 1999), initially as mentoring via phone (when it was known as distance or remote mentoring or tele-mentoring), then email, and now using a range of online tools (cyber-mentoring, or e-mentoring). Current virtual mentoring practice tends to use both synchronous tools (e.g. webinars, Voice Over Internet Protocol - such as Skype, and text chat), and asynchronous tools (emails, discussion forums, blog posts, and comments on posts).

\subsection{Mediated Agency}

Sociocultural theory has its foundations in the work of Vygotsky (1986), and later developed by theoreticians such as Wertsch (1998) and Engeström and Middleton (1996). Its central hypothesis is that human development, in particular higher order functions, arises from the social interactions of an individual with the external world (context) which includes people, objects, and events (Tharp \& Gallimore, 1988). Human interactions occurring within cultural and tool-mediated systems (Naismith et al, 2004) are seen as a fundamental aspect of learning. Systems of collective action and individual agency are culturally and historically situated, and significance is placed on mediational means (the space and tools, including language, along with concepts of 'rules', division of labour, the hierarchical structure of activity, and continuous development). These aspects are continuously negotiated, creating an 'irreducible tension' between agent(s) (mentor, mentees, community, teachers, students) and mediational frameworks (such as guidelines / norms, policies, roles, ethics and protocols - all that promote ways of thinking and acting) (Wertsch \& Rupert, 1993).

Four factors need to be present in any virtual professional learning offering that seeks to provide "a catalyst to move knowledge and goal setting into individual actions" (Winslow, DeGuzman, Kulbok, \& Jackson, 2014, p. 114), enhance mastery, make the most of role modelling, and reduce anxiety invoking experiences (Bandura, 1986):

Social persuasion - being involved in an environment that provides direct encouragement,

Opportunities to experience mastery,

Psychological factors - perceiving how to interpret emotional and physical factors when experiencing stress, and

Vicarious experiences - encountering examples of successful performance of a task / modelling of associated behaviours.

All four factors could, in theory, be provided through mentoring; however, to be more effective scaffolding should also be accessible via an (online) community, as well as through a support team for the mentoring initiative. Scaffolding is a central premise of sociocultural theory, which suggests that when learners are afforded opportunities for supported interaction with tasks, peers, and their community (Hausfather, 1996) the gap between a learner's existing knowledge or skills and desired 
learning goals can be bridged - in part by making the tasks manageable (Hmelo-Silver, Duncan, \& Chinn, 2007). This gap is known as the Zone of Proximal Development (ZPD). The process is iterative and is repeated as new knowledge and skills are assimilated (Owen \& Durham, 2008).

Professional learners, to be motivated and self-efficacious, need to feel as if they 'belong' to a community (Vygotsky, 1978), where there is also a variety of demands, competencies, and expertise so that members can scaffold one another through experiences (Lave \& Wenger, 1991). For the mentor (or those developing into a mentoring role) provision of opportunities that focus on boosting self-efficacy, such as sharing and discussing approaches and successes, has the potential to foster high-quality mentoring relationships (Larose, 2013). The mentor, in turn, helps mentees focus their attention on related tasks to promote engagement and commitment to learning and together evaluate progress as the mentee trials their learning in their workplace (Collis, Bianco, Margaryan, \& Waring, 2005). In addition, when self-efficacy for both mentor and mentee develops, there is a positive cycle, where confidence in their abilities grows, resulting in a greater tendency to apply themselves to demanding activities or new learning even in the face of challenges.

To be effective virtual learners, mentees need key skills (metacognitive as well as practical) to be able to interact within the environment as well as take on a high level of responsibility and initiative for their own learning (McLoughlin \& Marshall, 2000). Ludwig-Hardman and Dunlap (2003) suggest that the cognitive aspect of learner support (through guidance, mentoring, and coaching) is sometimes ignored. If the virtual environment is unfamiliar, working within a learner's ZPD and providing a choice of support at various skill levels, as well as through interaction between educators, the mentor and other support personnel (Ludwig-Hardman \& Dunlap, 2003) can scaffold the experience. As the learners acquire skills they experience 'success', and this can positively impact self-efficacy. However, without such scaffolding, learners are more likely to have negative experiences, which can lead to anxiety and frustration (Knowles, 1975).

\section{Background}

The Virtual Mentoring CASE model was developed from the findings of two studies, one that researched the experiences of students participating in the Virtual Learning Network Primary (VLNP) school, and the other that researched the professional learning experiences of educators who participated in the Virtual Professional Learning and Development (VPLD) programme.

The VLNP is a collaboration of schools that formally began in 2009 to enable small and rural primary schools to provide learning opportunities that were not available in their own schools. The VLNP connects schools through a collaborative online network (the Virtual School). Students learn via a weekly webinar facilitated by an eTeacher, as well as through an online community space (WeLearn), where they communicate with each other, as well as access and share resources. The research study associated with the VLNP sought to better understand how schools supported their primary-aged learners, in particular in relation to their growth toward independence. One aspect that was investigated was the role of school-based support staff (SBSS) in supporting virtual learners. A case study method was used with two primary schools, ranging from a school with less than fifty students to one with fourhundred-and-fifty students. Within these contexts, multiple perspectives were gathered in order to gain a deep, rich understanding of how primary schools support their students. To gather participants' personal experiences and understandings, qualitative data was collected via individual semi-structured interviews with the students, principals, teachers, school-based support staff and eteachers. A grounded theory analytical method was used to analyse the data, iterating between data collection and analysis (Seidel \& Urquhart, 2013; González-Teruel \& Abad-García, 2012).

The VPLD programme (which was instigated by the New Zealand Ministry of Education at the end of 2009) aimed to offer educators an opportunity to access virtual mentoring and an online Community of Practice ( $\mathrm{CoP})$, with multiple ways to participate that would support mentees to identify areas of professional growth based on their own needs - as well as those of their students, school and community (Owen, 2012). The programme had no formal 'content', associated accredited institution, or formal assessment. Mentees could participate in the programme for three years. In the first two years, they worked on their main professional development foci, and in the third year, they had the option to transition into a Developing Virtual Mentor (DVM) role. In a DVM role participants were partnered 
either with their own individual mentee, or a small group of mentees. At the same time, to build their own mentoring skills, the DVM continued to work with a mentor (mentor) from the VPLD team. Other support included a two-day face-to-face DVM wananga (educational seminar) each January, access to a series of online modules, and a monthly webinar.

A research study of the VPLD programme has been conducted since its inception, by the programme leader, that focused on evaluating the efficacy of the design of the programme. The case study method was used to aid understanding of a select subset as a distinct whole within its particular context (Merriam, 1998): in this case a professional development programme that used a virtual mentoring approach to provide professional development for education practitioners in Aotearoa New Zealand. Case studies are sometimes considered to be a qualitative technique, but may use quantitative information (Yin, 2009), which was in keeping with the mixed methods used in this study.

The authors of this paper, in keeping with a critical collaborative inquiry (Samaras, 2011) first analysed the findings from the two research studies (VLNP and VPLD) and independently identified emerging categories, before then cross-analysing to synthesise codes and themes. These codes and themes highlighted two essential stages in the approach to virtual learning and mentoring, and these are encapsulated in the Virtual Mentoring CASE model. Both of the stages contained two significant elements. The first was the foundation stage where the VLNP eTeacher or VPLD mentor was gathering contextual data and setting up administrative processes. The second was the transformative phase where the VLNP teacher or VPLD mentor put in place scaffolded supports to help learners grow their skills, knowledge and understandings. The empowering phase is when the learner could experience fundamental shifts in identity and/or practice.

While the Virtual Mentoring CASE model would be suitable for a wide range of age groups, it has been developed mainly for youth and adult learners engaged in a mentoring relationship. As such the discussion $d$ in the following sections refers only to the data and findings from the VPLD study.

\section{The Virtual Mentoring CASE Model: Packing the Essentials}

Virtual and face-to-face professional learning provision, in particular mentoring, have differences (Owen, 2015). Therefore virtual mentoring requires a model that recognises and supports, while also making the most of, the differences. The Virtual Mentoring CASE model is situated within a mediated agency framework, which helps illustrate the complexity of mentee opportunities and constraints within their own contexts, and in turn shapes the design of professional learning provision. It combines sufficient fluidity to enable mentor and mentees to personalise the professional learning experience, while also providing sufficient structure for them to feel comfortable on their learning journey.

Four stages are identified in the Virtual Mentoring CASE model. The 'Contextual data' and 'Administration process' stages form the foundation used to structure and signpost possible starting points on the learning journey. The 'Scaffolding' and 'Empowering process' stages make available personalised tools and approaches that the mentee selects based on their 'destination' (which may change over time as they progress). These aspects are likely to be different each time, and decisions are shaped by perceived needs.

Table 1. The virtual mentoring CASE model.

\begin{tabular}{l|l|l}
\hline & Stage & Explanation / Description \\
\hline 1 & \multirow{2}{*}{$\begin{array}{l}\text { Contextual data } \\
2\end{array}$} & $\begin{array}{l}\text { Building a relationship to gain: } \\
\text { A sense of the mentee as a holistic individual. } \\
\text { An idea of what they are hoping to achieve. }\end{array}$ \\
\hline \multirow{2}{*}{ process } & $\begin{array}{l}\text { Set up processes / support based on mentee needs, } \\
\text { values and beliefs, including, but not limited to: } \\
\text { Agreement on how / when to connect. } \\
\text { Cultural preferences. } \\
\text { Setting up a shared online space (Practioner Reflexive } \\
\text { Ongoing Practice Space - PROPs - document). } \\
\text { Joining and participating in online CoP. }\end{array}$ \\
\hline
\end{tabular}




\begin{tabular}{l|l|l}
\hline \multirow{3}{*}{ Scaffolding } & $\begin{array}{l}\text { What and who needs to be in place to: } \\
\text { Support each mentee so that they can attain their goals } \\
\text { / desires (personalised). } \\
\text { Adapt based on shifts in mentee needs and context(s). }\end{array}$ \\
\hline 4 & $\begin{array}{l}\text { Ongoing support and challenge to: } \\
\text { Help mentees grow their belief in their own capacity to } \\
\text { increase self-efficacy. } \\
\text { Achieve their aspirations and/or specific performance } \\
\text { goals. }\end{array}$ \\
\hline
\end{tabular}

\subsection{Contextual Data: Building the Relationship}

During the relationship building phase, a mentee provides some initial contextual data, which enables them to be partnered with a suitable virtual mentor. Prior to, and during the first meetings, the mentor and mentee get to know each other. The mentor will collect data about who the mentee 'is' (note that the following list is not exhaustive) including:

perception of self (in particular values, belief and sense of identity),

aspirations (including what they are already working on, and what they want to achieve),

social (especially working with other people, family, friends),

cultural (including work context, ethnicity),

historical (in particular background, prior knowledge, experience), and

environment (including sector and industry).

The understanding of the contextual data means that both mentor and mentee are also aware that "their actions are mediated by structural elements of their setting such as the resources available to them, the norms of their school, and externally mandated policies" (Lasky, 2005, p. 901).

\subsection{Administration Process}

Inherent to the administrative process, and underpinned by the contextual data, is the co-establishment of norms, boundaries and rules, which are negotiated and serve to shape ongoing processes and behaviour. Once the relationship building phase is underway, the mentor and mentee can: agree on how, when and how long to connect, discuss cultural preferences, negotiate etiquette during mentoring sessions, discuss understanding of roles, expectations and purpose, Identify key areas of support required, plan 'next steps' and interim goals (this may occur in the first couple of sessions, or in later sessions), agree to ongoing reflection and evaluation of the mentoring process, set up and work in a shared online space (Practioner Reflexive Ongoing Practice Space PROPS), and participate in the online CoP to support the social aspect of learning.

The administrative process ensures that the mentee is ready for the virtual environment, while also being confident in their ability to influence and shape sessions.

\subsection{Scaffolding}

Provision of scaffolding is dependent on understanding a mentee's identity, so that interactions and resources can be individualised. Scaffolding may be provided within the context of virtual mentoring sessions, or via the associated online community (by the mentor or fellow mentees), and will usually involve interpersonal interactions.

Scaffolding might include: provision of practical resources, simulations, representation of concepts in multiple ways, 
adapted materials and activities,

modelling and examples, and mediation of learning activities as they are shared through social interaction in the online community.

Scaffolding enables the provision of approaches that influence the development of strong self-efficacy, by supporting mentees to be more open to learning, take informed risks, and see non-achievement as formative.

\subsection{Empowering Process}

The empowering phase is relatively complex. It is the phase where the mentee, over time, grows as a professional. Many mentees will shift from dependence, to interdependence, and finally to intradependence. This process provides mentees with opportunities to develop autonomy and maintain the level of motivation required to persist to mastery by crafting an environment of distributed responsibility mediated for, by, and with the mentee. Mentees work with their mentor, other mentees, colleagues, and other interested stakeholders to make progress towards their aspirations and goals even when faced by challenges, in part through critical reflection, and evaluation of their capacity to apply, concepts and skills.

\section{Discussion: A Journey Shared}

"It is good to have an end to journey toward; but it is the journey that matters, in the end."

- (Le Guin, 1969. p109)

Having described the Virtual Mentoring CASE model, this section uses data from the VPLD research study to describe what each stage of the model looks like in action, along with some of the associated benefits, drawbacks and challenges.

\subsection{Contextual Data}

Where the context for professional learning is face-to-face, providers and learners share the same physical context. As such, both parties are privy to each other's reactions, including body language and facial expressions, which help signal how the professional development is being experienced. In the virtual environment of the VPLD programme there was greater reliance on a process, as well as oral / aural communication, to build relationships and collect data to inform first steps. Also, virtual mentors needed a wide set of skills and experience, in particular to recognise and accommodate needs and sociocultural factors that were less apparent in a virtual environment. The role required a commitment of time beyond what might be required face-to-face, to engage asynchronously (for example by email, and / or via the associated online $\mathrm{CoP}$ ), as well as directly with mentees. As such, additional skills such as time management, planning and boundary setting, were reported to be as important as mentoring skills.

The process of co-constructing an online document shared between the mentor and mentee meant that a record of the conversation was kept, that was read over and verified by the mentee during the note-taking process. Some mentees chose to type in ideas during sessions, and/or to share images in the document. One mentee observed that while their mentor took notes "I am able to say 'that's not quite what I meant', and we can discuss another word. It helps me clarify my own thoughts" (Mentee six, webinar comment, 2015). As such, the document formed a fundamental part of the collection of contextual data, in a format that encouraged the identification and unpacking of suppositions.

Although the VPLD study indicated that virtual mentoring relationships were slightly slower to develop, trust formed partly because virtual mentor and mentees were less able to make assumptions based on demographics (such as ethnicity, age, and physical appearance), as well reducing inferences about environmental influences. Some mentees also found the virtual environment a more comfortable medium to converse candidly; a place where they could be "honest about what they are experiencing" (Mentee four, mentor notes, 2011), which in turn enhanced the quality of the contextual data gathered. This sense of comfort was enhanced by the fact that the mentor was usually external to the mentee's organisation, and as such provided a more neutral, external sounding board: "someone from outside the 
school that I could confide in and ... an 'outside eye' to help me see the forest for the trees" (DVM3, reflection, 2016). In cases where there was low trust within the current work context, mentees found this sense of safety liberating. For instance, when Mentee eight faced ongoing issues she explained that "Our principal said he would fix the issue of the network...But he has not done it. It is a relief to share with you!" (Mentee 8, case study, 2013).

In summary, findings indicate that the notion of mediated agency provided by the Virtual Mentoring CASE model supported mentors to work with mentees in a way that recognised, and worked within, the constraints of a mentee's context, in a way that also collected rich contextual data, while also growing the mentor / mentee relationship.

\subsection{Administration Process}

The Virtual Mentoring CASE model provides the structure and multiple ways to connect, as well as ensuring a safe, quality professional learning experience. Clear structures and signposts helped the mentees identify where to start, and how they could build the skills to feel comfortable with the environment and the flexibility: "Knowing we have set a date to discuss ... [next steps] keeps me accountable. I've grown further and faster, than I would have otherwise' (DVM1, reflection, 2016). Mentees indicated that the structures, processes, and protocols, rather than stifling creativity and flexibility, provided a frame within which they found it was simple to: identify a clear starting point (which had the additional benefit of ensuring that ethics and protocols were discussed),

tailor their participation so that they didn't "feel overburdened. Everything works alongside things I am already doing" (survey response, 2012),

participate - for example, timing was flexible - "[I] can do it at a time that suits...usually evenings" (Mentee seven, mentor notes, 2011),

shape the PLD to suit the their needs, rather than having to adapt their goals and aspirations to the PLD,

access (geographically, physically, skill set wise, and environmentally) - "knowing that... [my mentor] is a Skype or email call away has left me feeling a lot more connected" (Mentee five, mentor notes, 2011),

afford - costs were kept low because there were no travel requirements, few administrative needs, and no premises,

draw on just when they needed the PLD,

take the PLD with them if they moved schools or roles,

keep track of their professional learning and progress,

connect - isolation was not confined to geography; some educators in large schools/institutions or cities reported feeling professionally isolated - "I ... realised ... how massive and pervasive professional isolation could be" (blog post, 2013); "I'm now connected to like-minded teachers across New Zealand ... you really don't need to feel stuck in a school any more" (Mentee 4, case study, 2012),

apply the PLD within their own context, and influence the overall culture of their organisation: "I have tried all sorts of interesting and varied things in the class during the year, ... [and] have shared so much with our staff" (Mentee 1, Case study, 2012), and align the mentoring with other PLD with which they are currently involved.

As with most PLD there were challenges. Some challenges were beyond the control of the project team, such as reliable access to a computer and the Internet - or at least a phone (especially those parts of Aotearoa New Zealand with no mobile phone coverage, and where the only landline is in the principal's office). In spite of the Administration process, every year between one to three participants in total dropped out during the initial stages of the VPLD programme for a variety of reasons including:

ill-health, family commitments,

a change in career, unsupportive leadership, or no reliable access to a computer and the Internet, or a phone.

(Owen, \& Whalley, 2016) 
While the structures were clear, the key thing that participants recognised was the flexibility. Mentees could develop at a pace that suited them, and choose the focus for the sessions. For example, in advance of a mentoring session, some mentees (or groups) would decide on their focus, whereas others would work more organically whereby the focus would emerge during the session. Mentees would also reflect on practice they had trialled, identify next steps and/or areas to develop, revisit their goals and discuss progress toward them, or work through a resource (such as a framework or tool) to see how (or if) it might support them in their professional practice. There were many approaches, and mentees would frequently change their approach for each mentoring session.

Findings indicated that optional interim support from their mentor was critical for the personalized guidance and motivation provided, especially when education practitioners were under stress (Owen, 2013). Some mentees stayed in touch with their mentor via email or a short call, or through comments in the shared online document between sessions, while others would only communicate during the mentoring sessions. There was therefore ongoing support if, and when, mentees needed it.

\section{$5.3 \quad$ Scaffolding}

Educators came into the VPLD programme with varying levels of comfort as self-directed online learners, and some required scaffolded support (Vygotsky, 1978). Taking responsibility for your own learning is not innate, so there is a need for guidance and support (Masouleh \& Jooneghani, 2012), and the findings indicated that scaffolding played an important role supporting learners towards developing independence in a sometimes unfamiliar environment. Scaffolding (as noted in the section above) was provided via resources and tools, as well as through interactions with peers to solve problems and develop skills. The variety of scaffolding meant that some of the common existing barriers to PLD, including confidence and skills sets in online spaces, were addressed. When encountering challenges some mentees reported that, because their mentor was able to support them when they "encountered barriers", as well as "push me in new directions, provide encouragement and network me with the wider e-Learning community", this "made all the difference" (Mentee seven, mentor notes, 2011). However, it was not like flicking a switch, and both Mentee one and Mentee two described ongoing crises of confidence. Mentee one indicated that "I ask[ed] myself if I'm good enough ... if I can cope with another year" (blog post, 2014), and Mentee two said she sometimes felt "as though it [teaching] is a waste of time" (mentor notes, 2014).

As part of the VPLD programme, alongside the virtual mentoring, the online $\mathrm{CoP}$ was facilitated to help ensure that there was a sense of situatedness, commonality, interdependency, and infrastructure (Hung, \& Chen, 2001). Through interdependency, the participants worked together to share a variety of challenges, competencies, and expertise (Lave, \& Wenger, 1991). As such, participants scaffolded each other's development in areas in which they were the most capable (Owen, 2013). As new educators entered the programme, a tendency was observed for existing mentees to 'pay it forward' as they moved into intra-dependence and assumed support roles. Online CoP members offered empathy, suggestions and support, and Mentee six indicated that she enjoyed "the group meetings in Adobe Connect, partly because of the sense of companionship that it gives, as well as the ideas and discussion" (mentor notes,

2011). Others identified as valuable:

access to a network where the "enthusiasm among the other members of the group is incredible - we just need to spread the word and get everyone on board" (mentor notes, 2012); "It was so good for drawing motivation, of seeing where I am at, and feeling more confident about what I am doing" (Mentee 4, case study, 2012).

a reciprocal (tuakana / teina) culture of learning - "the variety in relationships ... are mutually beneficial" (Mentee 5, case study 2012).

safe places to share and offer support - "Thanks to all the comments and feedbacks [sic] I received in my last post, I have decided to jump in and face my social studies class with another learning approach" (Mentee 2, case study, 2012).

a sense of belonging and being part of something bigger than their immediate professional context "I could read what others were doing. This gave me great ideas to try in my own class ... to be challenged" (Mentee 2, case study, 2012), and access to resources.

In summary, the VPLD programme provided scaffolded opportunities for educators to develop their own capability (skills, knowledge), and to participate socially with other supportive education 
professionals while also (re)defining their identity as a member of the professional community (Mentis, Ryba, \& Annan, 2001). As such, the combination of individualised support with a community of peers with whom to tease out and develop ideas, and access to relevant resources created a powerfully scaffolded, contextualised professional learning experience (Owen, 2013).

\subsection{Empowering Process}

The paradigm shift required for educators and leaders to be a supporter of students who helped them "actively interact with knowledge: to 'do things with it' - to understand, critique, manipulate, create and transform it" (Bull \& Gilbert, 2012, p. 6), was substantial. It required VPLD participants to explore their identity as an educator - to re-situate (Eraut, 2008) their beliefs, knowledge, learning and professional practice (Owen \& Dunmill, 2014). As they transitioned into the Empowering process experienced their shifting identity in a range of complex ways. Mentee eight, for instance indicated that, by deconstructing her identity as a teacher she experienced her role changing to one where she offered "assistance and help, not teaching...not saying remember this and remember that, but making suggestions, asking questions...guiding" (case study, 2013). Mentee two likewise described that "as a teacher [I] am now obsolete but my role as a facilitator is primordial and very active" (case study, 2012). And Mentee five mentioned that "I hadn't really acknowledged it or recognized it before, but I'm moving into a much more of a leadership role of some kind" (case study, 2012).

Some mentees developed high self-efficacy and moved rapidly into the Empowering process, while others took longer. The authors noticed that some moved through an iterative, reflexive process where they would carefully consider their beliefs or existing knowledge to develop understandings, and then, on each subsequent cycle, deepen these understandings. Sharing experiences within the intellectual construct of the VPLD online CoP resulted in gains in knowledge and skills (initially an integrative process where different types of knowledge intersected). With further trialling and development of their identity as practitioners and contributing members of the VPLD community (Mayo \& Macalister, 2004), the process proved transformative resulting in new synthesised forms of knowledge (Graham, 2011).

The shift wasn't always comfortable for the mentee or their immediate colleagues. For example, both Mentee four and Mentee six identified negative responses as an issue: Mentee four felt that she was constantly "struggling against senior managers who don't understand my pedagogy and are stuck in the traditional chalk and talk, lecture mode" (case study, 2013).

Mentees became more confident that they could influence their lives and environment, while also clearly recognising that they, in turn, were shaped by social, individual and mediational systems (Lasky, 2005). As such, they developed the self-efficacy that could "expand - or break down - previous hegemonies, closed, meanings, and habitual positioning" (Vähäsantanen, Saarinen, \& Eteläpelto, 2009, p. 6). For instance, Mentee five shared that:

For the first time I'm feeling really excited about teaching so it's reaching a sort of climax or pinnacle or crisis point or something .... It's allowed me to see the way I'm working but in a different way... but it's also giving me a way to know how to proceed forward, to change. Having that mentor helps to keep me on track ... helps me to believe in what I'm doing despite the fact that my teaching is starting to look very different to others around me (case study, 2012).

\section{Conclusion and Next Steps}

The four stages of the Virtual Mentoring CASE model played an important role in ensuring that the PLD 'came to' the mentees, had duration, and fitted within mentees' existing professional (and personal) lives, while also challenging them. Mentees were able to work toward their goals and aspirations, and were supported to be more open to learning, taking informed risks, and seeing non-achievement as formative. The virtual mentor worked to create online spaces, and used approaches that recognised factors that helped mentees develop strong self-efficacy, thereby increasing their ability to not only cope with change, but also to celebrate and embrace change.

The VPLD programme illustrates that a PLD provision, which combines access to a virtual mentor and a supportive online $\mathrm{CoP}$, is able to provide opportunities for social influence, feedback and 
modelling, to build a culture of trust, to support success and to use approaches that positively impact personal cognition. As such, it is likely that demand for models such as that offered by the VPLD programme will grow, and in turn increase momentum behind the reconceptualization of PLD. The virtual mentoring CASE model, underpinned by mediated agency, has the potential to guide the design of future virtual mentoring PLD provisions.

There are diverse reasons that people access virtual mentoring, and the Virtual Mentoring CASE model enables anyone in any context to provide professional development that is flexible, while also being structured enough to maintain the programme while meeting mentees' professional development needs, and helping them to realise the power of 'transformational realisation'.

The next steps for the development of the virtual mentoring CASE model is to transition it into a wider context to education, using the notion of mediational means (space and tools, including language) to develop the model further. By using the language of the environment in which the mentee is working, the model has the potential for transferability across socio-cultural domains (Uyanne, \& Oti, 2012), and work demographics.

\section{References}

1. Bandura, A. (1986). Social foundations of thought and action: A social cognitive theory. Englewood Cliffs, NJ, Prentice-Hall2.

2. Bolstad, R. and Gilbert, J., with McDowall, S., Bull, A., Boyd, S., \& Hipkins, R. (2012). Supporting Futureoriented Learning and Teaching: A New Zealand Perspective. Wellington: Ministry of Education. Retrieved January 19, 2013 from: http://www.educationcounts.govt.nz/publications/schooling/109306.

3. Bull, A., \& Gilbert, J. (2012). Swimming out of Our Depth? Leading Learning in 21st Century Schools. Wellington: NZCER. Retrieved October 14, 2013 from http://www.nzcer.org.nz/system/files/ Swimming\%20out\%20of\%20our\%20depth\%20final.pdf.

4. Collis, B., Bianco, M., Margaryan, A., \& Waring, B. (2005). Putting blended learning to work: a case study from a multinational oil company. Education, Communication \& Information, 5(3), 233-250.

5. Engeström, Y., \& Middleton, D. (1996). Cognition and communication at work. Boston, MA: Cambridge University Press.

6. Eraut, M. (2008). Learning from other people in the workplace. In: K. Hall, P. Murphy, \& J. Soler (Eds.), Pedagogy and practice - culture and identities. London: Sage.

7. Garvey, B. (2010). Mentoring in a coaching world. In E. Cox, T. Bachkirova, \& D. Clutterbuck (Eds.), The complete handbook of coaching (pp. 341-354). Oxford: Blackwell Publishing.

8. González-Teruel, A., \& Abad-García, M. F. (2012). Grounded theory for gene rating theory in the study of behavior. Library \& Information Science Research, 34(1), 31-36. doi:10.1016/j.lisr.2011.02.006.

9. Graham, C. R. (2011). Theoretical considerations for understanding technological pedagogical content knowledge (TPACK). Computers \& Education, 57(3), 1953-1960.

10.Hausfather, S. J. (1996). Vygotsky and Schooling: Creating a Social Context for Learning. Action in Teacher Education, 18, 1-10.

11.Hay, J. (1995). Transformational Mentoring: Creating Developmental Alliances. New York, NY: McGraw-Hill Publishing Co.

12.Hmelo-Silver, C. E., Duncan, R., \& Chinn, C. A. (2007). Scaffolding and Achievement in Problem-Based and Inquiry Learning: A Response to Kirschner, Sweller, and Clark (2006). Educational Psychologist, 42(2), 99-107.

13.Hung, D. W. L., \& Chen, D. (2001). Situated Cognition, Vygotskian Thought and Learning from the Communities of Practice Perspective: Implications for the Design of Web-Based E-Learning. Educational Media International, 38(1), 3-12.

14.Ives. Y. (2008). What is 'Coaching'? An Exploration of Conflicting Paradigms. International Journal of Evidence Based Coaching and Mentoring, 6(2), 100-113.

15.Knowles, M. (1975). Self-directed learning: A guide for teachers and learners. New York, NY: Cambridge, The Adult Education Company.

16.Kram, K. E. (1985). Mentoring at work: Developmental relationships in organizational life. Glenview, IL: Scott Foresman. 
17.Larose, S. (2013). Trajectories of mentors' perceived self-efficacy during an academic mentoring experience: What they look like and what are their personal and experimental correlates? Mentoring \& Tutoring: Partnership in Learning, 21(2), 150-174.

18.Lasky, S. (2005). A sociocultural approach to understanding teacher identity, agency and professional vulnerability in a context of secondary school reform. Teaching and teacher education, 21(8), 899-916.

19.Lave, J., \& Wenger, E. (1991). Situated learning: Legitimate peripheral participation. Cambridge: Cambridge University Press.

20.Le Guin, U. K. (1969). The left hand of darkness. New York: Ace.

21.Ludwig-Hardman, S., \& Dunlap, J. C. (2003). Learner support services for online students: Scaffolding for success. The International Review of Research in Open and Distributed Learning, 4(1).

22.Masouleh, N. S., \& Jooneghani, R. B. (2012). Autonomous learning: A teacher-less learning!. Procedia-Social and Behavioral Sciences, 55, 835-842.

23.Mayo, E., \& Macalister, N. (2004, March). Communities of learners: students learning while practising their skills. Paper presented at the Annual conference of the New Zealand Association for Cooperative Education.

24.Mentis, M., Ryba, K., \& Annan, J. (2001). Creating Authentic On-Line Communities of Professional Practice. Proceedings Australian Association for Research in Education Conference, Fremantle, 2001. Retrieved November 10, 2004, from http://www.ascilite.org.au/ajet/e-jist/docs/Vol5_No1/full_papers_5.htm

25.Merriam, S. (1998). Qualitative Research and Case Study Applications in Education. San Francisco, Jossey Bass.

26.McLoughlin, C., \& Marshall, L. (2000). Scaffolding: A model for learner support in an online teaching environment. In A. Herrmann \& M. M. Kulski (Eds.), Flexible futures in tertiary teaching. Proceedings of the 9th Annual Teaching Learning Forum, 2-4 February 2000. Perth: Curtin University of Technology. http://lsn.curtin.edu.au/tlf/tlf2000/mcloughlin2.html.

27.Naismith, L., Lonsdale, P., Vavoula, G., \& Sharples, M. (2004). Literature Review in Mobile Technologies and Learning. Retrieved April 12, 2008, from http://elearning.typepad.com/thelearnedman/mobile_learning/ reports/futurelab_review_11.pdf

28. Owen, H. (2012). Re-inventing PLD: Ensuring relevance and building resilience. Journal of Open, Flexible and Distance Learning, 16(1), 42-55.

29. Owen, H. (2013). Anticipating the future, participating in change: A paradigm shift for professional development. In V. Ham, R. Davey, \& J. Fenaughty (Eds.), Proceedings of the 16th International Conference on Thinking (ICOT) (pp. 128-135). Wellington, New Zealand: International Conference on Thinking.

30. Owen, H. (2015). Making the most of mobility: Virtual mentoring and education practitioner professional development, Research in Learning Technology 2015 (ALTJ), vol 23, [online] Available at: http://www.researchinlearningtechnology.net/index.php/rlt/article/view/25566

31. Owen, H., \& Dunmill, M. (2014). The Long Journey: Developing a Model of PLD for the Future. Australian Journal of Teacher Education, 39(1). Available from http://ro.ecu.edu.au/ajte/vol39/iss1/9.

32.Owen, H., \& Durham, E. (2008). The Research Skills and Projects blended learning course: From design to implementation. In M. Ramsden (Ed.), 7th Annual English Language Teaching Conference Proceedings Working with ELT Materials: From Design to Implementation (pp. 227-240). Muscat, Sultanate of Oman: Sultan Qaboos University Press.

33. Owen, H., Whalley, R. (2016). Facing down dragons and discovering gold: A tale of virtual mentoring and coaching. Proceedings of the DEANZ Conference 2016. Hamilton: University of Waikato. 79-84. Available at: http://conference.deanz.org.nz/wp-content/uploads/2014/07/DEANZ16-Conference-proceedingsFINAL.pdf.

34.Peled, Z., Peled, E., \& Alexander, G. (1994). An ecological approach for information technology intervention, evaluation, and software adoption policies. In E.L. Baker, \& H.F. O’Neil, Jr. (Eds.), Technology Assessment in Education and Training. Hillsdale, NJ: Erlbaum.

35.Rilke, R. M. (2012). Letters to a young poet. Courier Corporation.

36.Samaras, AP. (2011). Self-study teacher research: Improving your practice through collaborative inquiry. Thousand Oaks, CA: Sage Publications.

37.Seidel, S., \& Urquhart, C. (2013). On emergence and forcing in information systems grounded theory studies: The case of strauss and corbin. Journal of Information Technology, 28(3), 237-260. doi: http://dx.doi.org/ $10.1057 /$ jit.2013.17 
38.Single, P. B., \& Muller, C. (1999). Electronic mentoring; Issues to advance research and practice. Paper presented at the annual meeting of the International Mentoring Association, Atlanta, 15-17April 1999. Retrieved from: http://eric.ed.gov/?id=ED439683

39.Stoll, L. (2004). Developing professional learning communities: Messages for learning networks. Retrieved from http://plcwashington.org/cms/lib3/WA07001774/Centricity/Domain/42/developing-PLCs.pdf

40.Tharp, R. G., \& Gallimore, R. (1988). Rousing Minds to Life: Teaching, Learning, and Schooling in Social Context. Cambridge: Cambridge University Press.

41.Timperley, H. (2008). Teacher professional learning and development. Educational Practice. Series - 18 International Academy of Education \& International Bureau of Education Paris. UNESCO. Retrieved from http://www.ibe.unesco.org/fileadmin/user_upload/Publications/Educational_Practices/EdPractices_18.pdf

42.Uyanne, M. C., \& Oti, O. J. (2012). The Influence of Socio-cultural Domains on Communication. African Research Review, 6(4), 234-247.

43.Vähäsantanen, K., Saarinen, J., \& Eteläpelto, A. (2009). Between school and working life: Vocational teachers' agency in boundary-crossing settings. International journal of educational research, 48(6), 395-404. Retreived from: http://dx.doi.org.ezproxy.waikato.ac.nz/10.1016/j.ijer.2010.04.003

44.Vygotsky, L. S. (1978). Mind in society: The development of higher psychological processes. Cambridge, MA: Harvard University Press.

45.Vygotsky, L. S. (1986). Thought and language. Cambridge, MA: The MIT Press.

46.Wertsch, J. V. (1998). Mind as action. New York: Oxford University Press.

47.Wertsch, J., \& Rupert, L. (1993). The Authority of Cultural Tools in a Sociocultural Approach to Mediated Agency. Cognition and Instruction, 11(3/4), 227-239. Retrieved from: http://www.jstor.org.ezproxy.waikato.ac.nz/stable/3233737

48. Whiting, V., \& de Janaz, S. C. (2003). Mentoring in the 21st century: Using the internet to build skills and networks. Journal of Management Education, 28(3), 275-293.

49.Williams, P. (2014). Coaching vs psychotherapy: The great debate. Choice Magazine 2(1). 38-39.

50.Winslow, S., DeGuzman, P., Kulbok, P., \& Jackson, S. (2014). Nurses' self-efficacy and academic degree advancement. Journal for Nurses in Professional Development 30(3), p 110 - 116.

51.Yin, R. (2009). Case study research: Design and methods, (4th edn). Thousand Oaks, CA, Sage Publishing. 